\title{
The Influence of Model Parameters of Soil-Water Characteristic Curve to the Seepage
}

\author{
aYan LIANG, Liang ZHANG, Xin DU \& Chang-meng CHENG, ${ }^{b}$ Chao XIE, \\ 'Tong-lu LI \\ aSchool of Highway, Chang'an University, Xi'an, China; \\ Key Laboratory of Education Ministry on Highway Engineering of Special Region, Xi'an, China \\ bLanzhou Urban Development Investment Co., LTD, Lanzhou, China \\ 'Department of Geological Engineering, Chang'an University, Xi'an, China
}

KEYWORD: Soil-Water Characteristic Curve; parameter effects; seepage; hydraulic conductivity; sensitivity analysis; suction value; permeability testing

ABSTRACT: The model parameters of Soil-Water Characteristic Curve and the hydraulic conductivity may be obtained by the method of the back analysis according to the permeability test data. In order to raise the efficiency of the back analysis calculation, it is necessary to study the influence of the parameters of SWCC model to the seepage. The matrix suctions of Q2 loess were measured by the indoor test of the pressure plate extractor, and SWCC of Q2 loess was fitted with the Van Genuchten's three-parameter model. The influences of SWCC model parameters a, n, $\theta \mathrm{s}$, $\theta \mathrm{r}$ and Ksat on the range of seepage was studied. The results show that the air-entry value of Q2 loess is $18.48 \mathrm{kPa}$, the saturated volumetric water content is $45.82 \%$ and the residual volumetric water content is $3.91 \%$. It is found that the permeability sensitivity is different to different parameters. The influence of SWCC model parameters to the seepage depth from the big to the small is Ksat, $\theta \mathrm{s}, \mathrm{n}$, a and $\theta \mathrm{r}$, and that to the thickness of the unsaturated infiltration from the big to the small is Ksat, $\mathrm{n}$, $\theta \mathrm{s}$, a and $\theta \mathrm{r}$. The seepage range is the most sensitive with the change of Ksat, and there is the least sensitive with the change of $\theta r$. The influence of $\theta r$ is evidently lower than that of other parameters. The seepage range increases with the increase of parameters "a" and Ksat; while the seepage range reduces as parameters $n$ and $\theta$ s are added. Suggest that step size of the parameter is determined according to its influence degree to the seepage in the process of the back analysis of SWCC model parameters.

\section{INTRODUCTION}

Soil water characteristic curve (SWCC) is a curve which describes the relationship between suction and water content or the degree of saturation, and it is the constitutive relation of unsaturated soils. SWCC plays an important role in the study of the properties of unsaturated loess, which can be used to predict the volumetric deformation, shear strength, coefficient of permeability, diffusion and adsorption of unsaturated loess. At present, the studies of soil-water characteristic curve of loess are mainly based on indoor test such as Pressure Plate method, Salt Solution method, Filter Paper method, Potentiometer method, Tension Meter method, the method of Pore Size distribution (FREDLUND, 2002), Constant Flow method (LU, 2006), Transient Desorption and Absorption Moisture method (GUO, 2013), the method of numerical back analysis (WEI, 2008) and etc. CHEN (2011), LIU (2011), WANG (2011), ZHAO (2012), et al. have studied the influence of density or compaction degree, temperature, wetting - drying cycles, and consolidation pressure on the SWCC of the loess desorption by the laboratory test. JIAN, et al. (2014) has studied the SWCC of the loess in the Three Gorges Reservoir Area in the process of absorbing moisture by in-situ test.

With the soil-water characteristic curve and hydraulic conductivity, the seepage field can be calculated. On the contrary, model parameters of Soil-Water Characteristic Curve and hydraulic conductivity can be obtained based on the measured seepage field by the method of the back analysis calculation. In order to improve the efficiency of back analysis, it is necessary to study the influence of 
the parameters of SWCC model on the seepage. This study employed Van Genuchten experiential formula (VG model) to fit the experimental data based on the indoor experiment with pressure plate extractor and obtained the water-soil characteristic curve of Q2 loess sampled from the Southern Jingyang Plateau in Shaanxi province. On this basis, the author studied the influence of SWCC model parameters and hydraulic conductivity on the seepage.

\section{THE SUCTION TEST}

The Southern Jingyang Plateau mainly is composed of soil sequence of Pleistocene loess and Paleosol. Q2 loess of middle Pleistocene is the mainly part of the southern Jingyang Plateau, including the second to the eighth layers of Loess and Paleosol, thickness 40-54m. Q2 loess is dark yellow, well distributed and middle close-grained.

Took undisturbed Q2 loess as sample, ascertained the density of soil with cutting ring knife, determined water content by oven drying method and determined organic matter content by potassium dichromate titrimetric method. The basic physical properties of Q2 loess are shown in Table 1.

Table 1 The physical properties of the undisturbed $Q_{2}$ loess

\begin{tabular}{|c|c|c|c|c|c|c|}
\hline $\begin{array}{l}\text { Spe- } \\
\text { cific } \\
\text { gravi- } \\
\text { ty } \\
G_{\mathrm{s}}\end{array}$ & $\begin{array}{c}\text { Nat- } \\
\text { ural } \\
\text { den- } \\
\text { sity } \\
\rho \\
/ \\
(\mathrm{g} / \mathrm{c} \\
\left.\mathrm{m}^{3}\right)\end{array}$ & $\begin{array}{l}\text { Natu- } \\
\text { ral } \\
\text { water } \\
\text { con- } \\
\text { tent } \\
\quad w \\
/ \%\end{array}$ & $\begin{array}{l}\text { Dry } \\
\text { den- } \\
\text { sity } \\
\rho_{\mathrm{d}} / \\
(\mathrm{g} / \mathrm{c} \\
\left.\mathrm{m}^{3}\right)\end{array}$ & $\begin{array}{l}\text { Liq- } \\
\text { uid } \\
\text { limit } \\
w_{\mathrm{L}} \\
/ \%\end{array}$ & $\begin{array}{l}\text { Plas- } \\
\text { tic } \\
\text { limit } \\
w_{\mathrm{p}} \\
/ \%\end{array}$ & $\begin{array}{l}\text { Or- } \\
\text { gan- } \\
\text { ic } \\
\text { mat- } \\
\text { ter } \\
\text { cin- } \\
\text { tent/ } \\
\%\end{array}$ \\
\hline 2.72 & 1.57 & 8.80 & $\begin{array}{c}1.44 \\
3\end{array}$ & 26.2 & 21.6 & 0.23 \\
\hline
\end{tabular}

The determination of soil-water characteristic curve is the key to study the mechanical properties of unsaturated soils. Pressure plate instrument, which was produced by Soil Moisture Equipment Corporation, was used to measure the matrix suction of Q2 loess. Table 2 is experimental data.

Table 2 Measured matrix suction and volumetric water content of $Q_{2}$ loess

\begin{tabular}{rl}
\hline $\begin{array}{l}\text { Matrix } \\
\text { suction } \\
\text { /kpa }\end{array}$ & $\begin{array}{l}\text { Volu- } \\
\text { metric } \\
\text { water } \\
\text { content }\end{array}$ \\
\hline 0 & 0.4582 \\
10 & 0.4564 \\
20 & 0.4207 \\
30 & 0.3673 \\
40 & 0.3131 \\
50 & 0.2604 \\
60 & 0.2011 \\
70 & 0.1949 \\
80 & 0.1778 \\
90 & 0.1773 \\
100 & 0.1626 \\
450 & 0.1362 \\
\hline
\end{tabular}

In all kinds of mathematical models describing Soil-Water Characteristic Curve, VG model (VAN GENUCHTEN, 1980) is widely used in Geotechnical engineering, which is as follows: 


$$
\theta_{w}=\theta_{r}+\frac{\theta_{s}-\theta_{r}}{\left[1+\left(\frac{\Psi}{a}\right)^{n}\right]^{m}}
$$

Where $\theta_{\mathrm{w}}$ is the volumetric water content;

$\theta_{\mathrm{s}}$ is the saturated volumetric water content, According to the density of soil, the density of soil particle and the water content, calculated and obtained the saturated volumetric water content of Q2 loess was 0.4582 .

$\theta_{\mathrm{r}}$ is the residual volumetric water content;

$\Psi$ is negative pore water pressure;

$a(\mathrm{kPa}) 、 n$ and $m$ are curve-fitting parameters. The $m$ is determined by the shape of Soil-Water Characteristic Curve. Suppose $m=1-1 / n$ in this paper.

The matrix suction of Q2 loess was measured by the pressure plate extractor. Used VG model to express the relationship between the volumetric water content and matrix suction (see Figure 1), and got VG model parameters of Q2 loess $\theta \mathrm{r}=0.0391, a=40.0 \mathrm{kPa}, n=2.50, m=0.6$, so the soil-water characteristic curve of Q2 loess was determined. Analyzed the experimental data, and got that air entry value was $18.48 \mathrm{kPa}$.

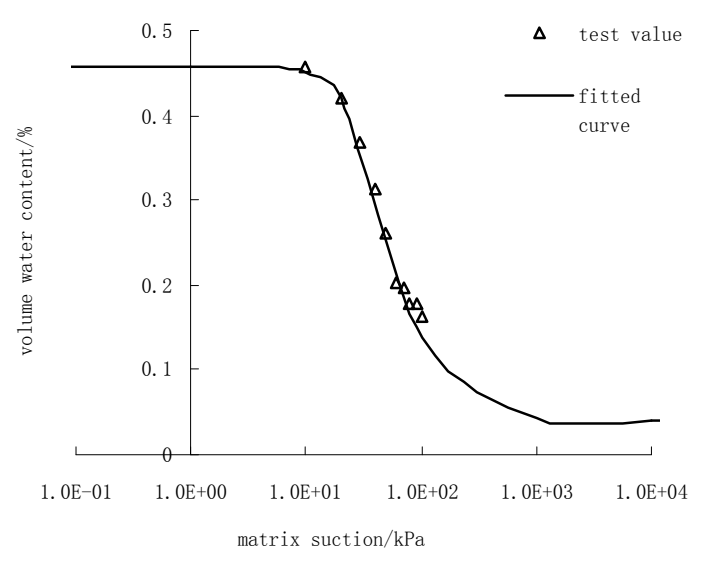

Fig.1 The fitting soil-water characteristic curves

\section{RESEARCH METHOD}

In order to study the influence of the variation of SWCC model parameters on seepage, calculated seepage using Geo-Studio software which is widely used in Geotechnical engineering based on the test results of the pressure plate extractor.

In this paper, calculated seepage range when the pore water pressure was $-20 \mathrm{kPa}$ and $-30 \mathrm{kPa}$, so that analyzed the influence of parameters on the seepage. The SWCC model parameters are changed, which means that SWCC is different. Calculating seepage needs to use hydraulic conductivity $K_{\text {sat }}$. According to the test data, the hydraulic conductivity of Q2 loess is $6.8^{*} 10^{-6} \mathrm{~m} / \mathrm{s}$. Took the model parameters obtained from the tests as reference parameters, changed any one of the parameters $a$ 、 $n 、 \theta_{\mathrm{s}} 、 \theta_{\mathrm{r}}$ and $K_{\text {sat. }}$ Supposing the other parameters are not changed, we studied the influence of the parameter variance on the seepage. For the five parameters of $a 、 n 、 \theta_{\mathrm{s}}, \theta_{\mathrm{r}}$ and $K_{\text {sat }}$, the method of parameters variation is the test value times 0.8 and 1.2 respectively. 


\section{THE INFLUENCE OF MODEL PARAMETERS ON SEEPAGE}

\section{Double loop permeability test}

Through the field investigation, chose the site of Wangjia village, Gaozhuang town, Jingyang

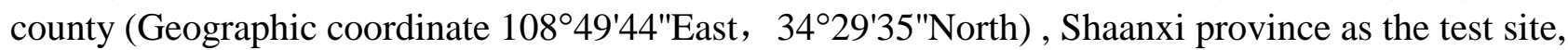
doing double loop permeability test.

After chose the test site, dug until fresh soil and flatted surface in every test. Beat the double loop into $10 \mathrm{~cm}$ deep under the soil surface. The diameter of inner ring is $30.3 \mathrm{~cm}$, the diameter of outer ring is $48.5 \mathrm{~cm}$. Both height of inner and outer ring all is $25 \mathrm{~cm}$. Spread a thin layer of sand soil over the soil surface in the ring, protected the soil surface not to be destroyed during the test. Fast injected water to the soil surface until $5 \mathrm{~cm}$ height in the inner and outer ring, and recorded the amount of water injected into the inner loop. During the test, one person was responsible for observing water level in inner and outer rings. If the water level dropped, replenished water at once, kept the water head $5 \mathrm{~cm}$ height above soil surface, and recorded the amount of water rejected into the inner loop. After reaching the constant seepage, continued test for a period of time. After the permeability test lasted $180 \mathrm{~min}$, stopped injecting water.

In order to see the seepage profile and study the seepage characteristics, excavated soil along the symmetry plane of test after the test was stopped. The water seepage in the soil can be observed directly by color (Figure 2 is the cross-section after the permeability test). Observed the color of the loess, sampled until the color of the soil reaches the color of the natural soil, and measured the water content of samples by the oven-drying method.

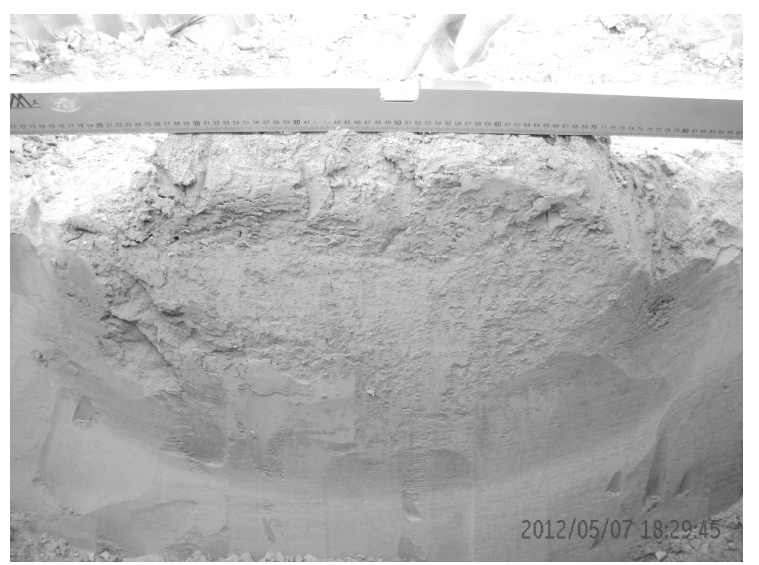

Fig. 2 The cross-section after the permeability test of $Q_{2}$ loess

\section{Numerical calculation model}

Seepage equation in numerical calculation is as follows:

$$
\frac{\partial}{\partial x}\left(K_{x} \frac{\partial H}{\partial x}\right)+\frac{\partial}{\partial y}\left(K_{y} \frac{\partial H}{\partial y}\right)+Q=m_{w} \gamma_{w} \frac{\partial H}{\partial t}
$$

Where, $H$ is total head; $K_{x}$ is the hydraulic conductivity in the $\mathrm{X}$ direction, $K_{y}$ is the hydraulic conductivity in the Y direction; $Q$ is flux; $m_{\mathrm{w}}$ is the coefficient of volume compressibility, $\gamma_{w}$ is unit weight of water, $t$ is time

According to the above research methods, the model parameters were determined as in table 3 . 
Table 3 The values of model parameters

\begin{tabular}{|c|c|c|c|c|c|c|c|}
\hline $\begin{array}{l}\text { Seri- } \\
\text { al } \\
\text { num } \\
\text { ber }\end{array}$ & $\begin{array}{l}\text { pa- } \\
\text { ra } \\
\text { me } \\
\text { ter }\end{array}$ & $\begin{array}{l}\text { mul } \\
\text { tipl } \\
\mathrm{e}\end{array}$ & $a$ & $n$ & $\theta \mathrm{s}$ & $\Theta \mathrm{r}$ & $\begin{array}{l}\text { Ksat } \\
/ \mathrm{m} / \mathrm{s}\end{array}$ \\
\hline \multirow[t]{2}{*}{1} & \multirow[t]{4}{*}{$a$} & 0.8 & 32 & 2.5 & 0.45 & 0.03 & 6.80 \\
\hline & & & & & 82 & 91 & E-06 \\
\hline \multirow[t]{2}{*}{2} & & 1.2 & 48 & 2.5 & 0.45 & 0.03 & 6.80 \\
\hline & & & & & 82 & 91 & E-06 \\
\hline \multirow[t]{2}{*}{3} & \multirow[t]{4}{*}{$n$} & 0.8 & 40 & 2 & 0.45 & 0.03 & 6.80 \\
\hline & & & & & 82 & 91 & E-06 \\
\hline \multirow[t]{2}{*}{4} & & 1.2 & 40 & 3 & 0.45 & 0.03 & 6.80 \\
\hline & & & & & 82 & 91 & E-06 \\
\hline \multirow[t]{2}{*}{5} & \multirow[t]{4}{*}{$\Theta \mathrm{s}$} & 0.8 & 40 & 2.5 & 0.36 & 0.03 & 6.80 \\
\hline & & & & & 66 & 91 & E-06 \\
\hline \multirow[t]{2}{*}{6} & & 1.2 & 40 & 2.5 & 0.54 & 0.03 & 6.80 \\
\hline & & & & & 98 & 91 & E-06 \\
\hline \multirow[t]{2}{*}{7} & \multirow[t]{4}{*}{$\Theta \mathrm{r}$} & 0.8 & 40 & 2.5 & 0.45 & 0.03 & 6.80 \\
\hline & & & & & 82 & 13 & E-06 \\
\hline \multirow[t]{2}{*}{8} & & 1.2 & 40 & 2.5 & 0.45 & 0.04 & 6.80 \\
\hline & & & & & 82 & 69 & E-06 \\
\hline \multirow[t]{2}{*}{9} & \multirow{4}{*}{$\begin{array}{r}K \mathrm{~s} \\
\text { at }\end{array}$} & 0.8 & 40 & 2.5 & 0.45 & 0.03 & 5.44 \\
\hline & & & & & 82 & 91 & E-06 \\
\hline \multirow[t]{2}{*}{10} & & 1.2 & 40 & 2.5 & 0.45 & 0.03 & 8.16 \\
\hline & & & & & 82 & 91 & E-06 \\
\hline
\end{tabular}

Refer to the seepage condition of double loop permeability test, the axial symmetry was considered in the numerical calculation. The geometry model of saturated - unsaturated seepage was established as Figure 3, in which model width was $1.5 \mathrm{~m}$, height was $5.0 \mathrm{~m}$. Model was divided by quadrilateral mesh, and grid length was $0.02 \mathrm{~m}$.

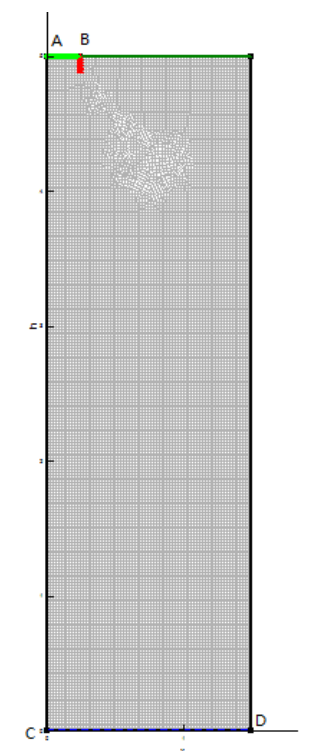

Fig. 3 FEM mesh of the infiltration calculation 
Initial condition was that the boundary $C D$ was the initial water level in figure 3 . The boundary conditions was that the boundary $\mathrm{AB}$ (Length is $24.25 \mathrm{~cm}$ ) had $5 \mathrm{~cm}$ high constant head and flow was 0 along the other boundary. We calculated the seepage after test 180minutes.

\section{Sensitivity analysis of model parameters to seepage}

In this paper, take $S_{\mathrm{sh}}=\frac{\Delta h}{\Delta P_{a}}$ as the depth sensitivity of seepage, which expresses the influence of the parameters variation on seepage depth. In the expression $S_{\mathrm{sh}}, \Delta h$ is the variation of seepage depth, $\Delta P_{a}$ is the percentage variation of model parameters. In a similar way, $S_{\mathrm{uh}}=\frac{\Delta h_{\mathrm{u}}}{\Delta P_{a}}$ is defined as the thickness sensitivity of unsaturated seepage, which expresses the influence of the parameters variation on the thickness of the unsaturated seepage, in the expression $S_{\mathrm{uh}}, \Delta h_{\mathrm{u}}$ is the thickness variation of unsaturated seepage. The average value of sensitivity is calculated by the range from the $-20 \%$ test values to $20 \%$ test values. The test values are that hydraulic conductivity $K_{\mathrm{sat}}=6.8^{*} 10^{-6} \mathrm{~m} / \mathrm{s}, a=40.0 \mathrm{kPa}, n=2.50, \theta_{\mathrm{s}}=0.4582, \theta_{\mathrm{r}}=0.0391$. In this paper, $h$ is the seepage depth corresponded to the pore water pressure $-30 \mathrm{kPa}, h_{\mathrm{u}}$ is the variation range of seepage depth corresponded to the pore pressure from $-20 \mathrm{kPa}$ to $-30 \mathrm{kPa} . \Delta P_{a}=20 \%-(-20 \%)=40 \%$. The calculation results are listed in table 5, in which "+" indicates that the seepage depth or the thickness of unsaturated soil increases with the increase of the parameters, and "-" indicates that the seepage depth or the thickness of unsaturated soil decreases with the increase of the parameters.

\section{Table 4 The Seepage depth}

\begin{tabular}{|c|c|c|c|c|}
\hline & \multicolumn{2}{|c|}{$\begin{array}{c}\text { Seepage } \\
\text { depth in } \\
\text { the pore } \\
\text { water } \\
\text { pressure - } \\
30 \mathrm{kPa} \\
/ \mathrm{m}\end{array}$} & \multicolumn{2}{|c|}{$\begin{array}{c}\text { Seepage } \\
\text { depth in } \\
\text { the pore } \\
\text { water } \\
\text { pressure - } \\
20 \mathrm{kPa} \\
/ \mathrm{m}\end{array}$} \\
\hline \multirow{3}{*}{$\begin{array}{l}\text { Para- } \\
\text { meter } \\
\text { value }\end{array}$} & 0.8 & 1.2 & 0.8 & 1.2 \\
\hline & tim & tim & tim & tim \\
\hline & es & es & es & es \\
\hline \multirow[t]{2}{*}{$a$} & 0.7 & 0.7 & 0.4 & 0.4 \\
\hline & 065 & 885 & 204 & 455 \\
\hline \multirow[t]{2}{*}{$n$} & 0.8 & 0.6 & 0.4 & 0.4 \\
\hline & 210 & 892 & 534 & 167 \\
\hline \multirow[t]{2}{*}{$\theta s$} & 0.8 & 0.6 & 0.4 & 0.3 \\
\hline & 035 & 304 & 494 & 380 \\
\hline \multirow[t]{2}{*}{$\theta r$} & 0.6 & 0.6 & 0.3 & 0.3 \\
\hline & 806 & 804 & 447 & 464 \\
\hline \multirow[t]{2}{*}{ Ksat } & 0.5 & 0.7 & 0.3 & 0.3 \\
\hline & 680 & 563 & 002 & 781 \\
\hline
\end{tabular}

Table 5 The sensitivity of the parameters to infiltration

\begin{tabular}{ccc}
\hline Parameter & $S_{\mathrm{sh}}$ & $S_{\mathrm{uh}}$ \\
\hline$a$ & +0.21 & +0.14 \\
$n$ & -0.33 & -0.24 \\
$\theta \mathrm{s}$ & -0.43 & -0.15 \\
$\theta \mathrm{r}$ & $-5 \mathrm{E}(-4)$ & -0.005 \\
Ksat & +0.47 & +0.28 \\
\hline
\end{tabular}


From table 5 we can know that

(1) The seepage range and the thickness of unsaturated zone have different sensitivities to the parameters variation. The sensitivity degree of the seepage range to the parameters variation is $S_{\mathrm{sh}}\left(K_{\mathrm{sat}}\right)>S_{\mathrm{sh}}\left(\theta_{\mathrm{s}}\right)>S_{\mathrm{sh}}(n)>S_{\mathrm{sh}}(a)>S_{\mathrm{sh}}\left(\theta_{r}\right)$, and the sensitivity degree of unsaturated thickness to the parameters variation is $S_{\mathrm{uh}}\left(K_{\mathrm{sat}}\right)>S_{\mathrm{uh}}(n)>S_{\mathrm{uh}}\left(\theta_{\mathrm{s}}\right)>S_{\mathrm{uh}}(a)>S_{\mathrm{uh}}\left(\theta_{\mathrm{r}}\right)$

(2) The seepage range increased with the increase of the parameters $a$ and $K_{\text {sat }}$. The seepage range decreases with the increase of the parameters $n, \theta_{\mathrm{s}}$ and $\theta_{\mathrm{r}}$.

(3) The seepage depth and the thickness of unsaturated soil are the most sensitive to the change of $K_{\text {sat }}$, and have the least sensitive to the change of the residual volumetric water content . The influence of the residual volumetric water content $\theta_{\mathrm{r}}$ is much smaller than that of other parameters.

As for the influence of various parameters on the seepage depth, the influence of $\theta_{\mathrm{s}}$ is -0.43 , which is second influence. The impact of $n$ is -0.33 , ranking third. As for the influence of the thickness of the unsaturated seepage, the influence of $n$ is second influence, which is -0.24 . The influence of $n$ is greater to the unsaturated permeability than that of $\theta_{\mathrm{s}}$, which is different from the influence to seepage depth. The sensitivity of $\theta_{\mathrm{s}}$ and " $a$ " to the unsaturated thickness were -0.15 and 0.14 respectively. The absolute value of those two sensitivities is almost same, but the thickness of unsaturated soil decreased with the increase of $\theta_{\mathrm{s}}$, and the thickness of unsaturated soil increased with the increase of $a$. When SWCC Model parameters and hydraulic conductivity are determined by the back analysis method, we should determine the step size of parameters according to the permeability sensitivity of parameters so that improve the calculation efficiency.

\section{CONCLUSIONS}

Obtain the following conclusions through research,

1) The air entry value of Q2 loess is $18.48 \mathrm{kPa}$. Saturated volumetric water content is $45.82 \%$, residual volumetric water content is $3.91 \%$, and residual saturation degree is $8.53 \%$.

2 ) In the five parameters $K_{\text {sat }}, a, n, \theta_{\mathrm{s}}, \theta_{\mathrm{r}}$, changing $K_{\text {sat }}$ may cause the largest change in the range of seepage, while changing $\theta \mathrm{r}$ may cause the smallest change.

3 ) The seepage depth increases with the increase of parameters " $a$ " and $K_{\text {sat }}$. The seepage depth decreases with the increase of parameters $n$ and $\theta_{\mathrm{s}}$.

4) The influence of residual volumetric water content on the seepage is much smaller than the others.

5) The sensitivity of different model parameters is very different. When SWCC model parameters and hydraulic conductivity are determined by the method of back analysis, for parameters of small sensitivity, calculation step size may be increased. Calculation step size should be decreased to those parameters with big sensitivity.

\section{ACKNOWLEDGEMENTS}

This research work was aided by National Natural Science Foundation of China (No.NSFC41172256, NSFC-41372329). The support of this agency is gratefully acknowledged.

\section{REFERENCES}

1) CHEN Cun-li, CHU Feng, LI Lei-lei, et al. 2011. Soil-water characteristics OF of unsaturated undisturbed loess under confined compression condition. Chinese Journal of Rock Mechanics and Engineering, 30(3): 610-615.

2)FREDLUND M D, WILSON G W, FREDLUND D G. 2002. Use of the grain-size distribution for estimation of the soil-water characteristic curve. Canadian Geotechnical Journal39(5): 11031117. 
3) GUO Long, LIU Qing-bing, WANG Jing-e, et al. 2013. Soil Water Characteristic Curve of Malan Loess by Transient Water Release and Imbibitions Method. Journal of Yangtze River Scientific Research Institute, 30(11): 67-71.

4) JIAN Wen-xing, XU Qiang, WU Han, et al. 2014. Study of unsaturated hydraulic parameters of Huangtupo landslide in Three Gorges reservoir area. Rock and Soil Mechanics, 35(12): 35173522.

5)LIU Feng-yin, ZHANG Zhao, ZHOU Dong, et al. 2011. Effects of initial density and dryingwetting cycle on soil water characteristic curve of unsaturated loess. Rock and Soil Mechanics, 32(Z2): $132-136,142$.

6) LU N, WAYLLACE A, CARRERA J, et al. 2006. Constant flow method for concurrently measuring soil-water characteristic curve and hydraulic conductivity function. Geotechnical Testing Journal, 29(3): 230-241.

7) VAN GENUCHTEN M T. 1980. A closed-form equation for predicting the hydraulic conductivity of unsaturated soils. Soil Science Society of Americal Journal, 44(5): 892-898.

8)WANG Xie-qun, ZOU Wei-lie, LUO Yi-dao, et al. 2011. SWCCs and influence of temperature on matrix suction under different compaction degree. Chinese Journal of Geotechnical Engineering, 33(3): $368-372$.

9) WEI Jin-bing, DENG Jian-hui, GAO Chun-yu, et al. 2008. Unsaturated seepage analysis and back analysis of permeability coefficient for xietan landslide in three gorges reservoir area. Rock and Soil Mechanics, 29(8): 2262-2266.

10) ZHANG Zhao, LIU Feng-yin, ZHAO Xu-guang, et al. 2013. A soil water characteristic curve model considering void ratio variation with stress. SHUILI XUEBAO, 44(5): 578-585.

11) ZHAO Tian-yu, WANG Jin-fang. 2012. Soil-water characteristic curve for unsaturated loess soil considering density and wetting-drying cycle effects. Journal of Central South University (Science and Technology), 43(6): 2445-2453. 